\title{
Executive functions in developmental dyslexia
}

\author{
Pamela Varvara ${ }^{1,2+}$, Cristiana Varuzza ${ }^{1+}$, Anna C. P. Sorrentino ${ }^{1}$, Stefano Vicari ${ }^{1}$ and Deny Menghini ${ }^{1 *}$ \\ ${ }^{1}$ Neuroscience Department, Children's Hospital Bambino Gesù, Rome, Italy \\ ${ }^{2}$ Psychology Department, Libera Università Maria Ss. Assunta, Rome, Italy
}

Edited by:

Alan J. Power, University of

Cambridge, UK

Reviewed by:

Laurie E. Cutting, Vanderbilt

University, USA

Susan Nittrouer, The Ohio State

University, USA

\section{*Correspondence:}

Deny Menghini, Neuroscience

Department, Children's Hospital

Bambino Gesù, Piazza Sant'Onofrio

4, Rome 1-00165, Italy

e-mail:deny.menghini@opbg.net

${ }^{\dagger}$ These authors have contributed equally to this work.

The present study was aimed at investigating different aspects of Executive Functions (EF) in children with Developmental Dyslexia (DD). A neuropsychological battery tapping verbal fluency, spoonerism, attention, verbal shifting, short-term and working memory was used to assess 60 children with DD and 65 with typical reading (TR) abilities. Compared to their controls, children with DD showed deficits in several EF domains such as verbal categorical and phonological fluency, visual-spatial and auditory attention, spoonerism, verbal and visual short-term memory, and verbal working memory. Moreover, exploring predictive relationships between EF measures and reading, we found that spoonerism abilities better explained word and non-word reading deficits. Although to a lesser extent, auditory and visual-spatial attention also explained the increased percentage of variance related to reading deficit. EF deficits found in DD are interpreted as an expression of a deficient functioning of the Central Executive System and are discussed in the context of the recent temporal sampling theory.

Keywords: developmental disabilities, working memory, central executive system, attention, phonological processing

\section{INTRODUCTION}

Executive functions (EF) are a set of high cognitive abilities that control and regulate other functions and behaviors (Welsh et al., 1991). They may involve abilities such as selectively processing information in the environment, retaining task-relevant information in an accessible state over time, making a plan by selecting a sequence of actions to achieve a goal, inhibiting a verbal or motor response, successfully adapting responses to changes in situations and environments, problem solving and self monitoring (Welsh et al., 1991; Pennington and Ozonoff, 1996; Friedman et al., 2006).

EF deficits have been described in several developmental disorders. Attention, working memory, inhibitory control, and flexible thinking deficits have been documented in individuals with attention and hyperactivity disorders (Sergeant et al., 2002; Corbett et al., 2009; Abad-Mas et al., 2011; Pani et al., 2013); inhibition of responses and planning deficits have been described in children with autism (Rinehart et al., 2001; Hill, 2004; Kenworthy et al., 2005; Robinson et al., 2009); planning and memory deficits have been reported in fetal alcohol spectrum disorder (Rasmussen, 2005; Green et al., 2009; Pei et al., 2011). Deficits in a set of EF have also been documented in genetic syndromes associated with intellectual disability (Costanzo et al., 2013). Moreover, a recent meta-analysis (Booth et al., 2010) has highlighted that children with reading disability have difficulties in several EF, including maintaining relevant information in WM, inhibition of irrelevant information, and accessing material in long-term memory.

Indeed, deficits in WM have been mainly investigated using span tasks and are considered one of the major defining characteristics of Developmental Dyslexia (DD) (Willcutt et al., 2005; Swanson et al., 2009, 2010; Bacon et al., 2013). Both verbal and visual-spatial components of WM have been found impaired in children (Poblano et al., 2000; Brosnan et al., 2002; Helland and
Asbjørnsen, 2004; Martinussen and Tannock, 2006; Smith-Spark and Fisk, 2007; Menghini et al., 2011) and adults (Smith-Spark et al., 2003; Alloway and Alloway, 2013) with DD. In the light of Baddeley's model, the reduced performance of dyslexics in memory span tasks involving both verbal and visual-spatial modalities may be interpreted as an expression of deficient functioning of the Central Executive component of WM. The tripartite WM model (Baddeley and Hitch, 1974; Baddeley and Logie, 1999; Baddeley, 2000, 2001) includes a Central Executive System (CES) responding to different cognitive functions (e.g., attention, activeinhibition, planning, updating, maintenance and integration of information) and two peripheral slave systems devoted to the temporary storing and rehearsing of information pertaining to a single modality (visual-spatial sketchpad and articulatory loop). The CES coordinates the two slave systems, integrating their storage capacities and making available attentional resources for online processing of incoming information. It has been proposed that the CES may be analogous to the Supervisory Attentional System (SAS) described by Shallice and colleagues (Norman and Shallice, 1986; Shallice and Burgess, 1993). Indeed, the SAS is defined as a conscious control mechanism that resolves interference and allows attentional control over action. CES and SAS not only have a critical control function in WM, but are also involved in several processes requiring higher-order cognitive control. Accordingly, Kane and Engle (2002) define controlled attention as an executive control capability that can effectively maintain stimulus, goal, or context information in an active, easily accessible state in the face of interference, effectively inhibiting goal-irrelevant stimuli or responses (Kane et al., 2001).

Deficits in visual-spatial attention in DD have also been found using tasks which evaluate orientation, focusing, shifting attention and visual search (Helland and Asbjørnsen, 2000; Altemeier et al., 2008; Menghini et al., 2010). Deficits in auditory attention 
have also been found using discrimination speech tasks (e.g., Casco and Prunetti, 1996; Facoetti et al., 2000; Buchholz and McKone, 2004; Valdois et al., 2004; Dufor et al., 2007). Hari and Renvall (2001) and Laasonen et al. (2012) have suggested that children with DD may suffer from sluggish attentional shifting (i.e., engaging and disengaging attention) as revealed by tasks assessing sustained and divided attention, auditory saltation illusion, auditory pitch streaming sequence, and attentional blink.

Furthermore, studies in DD have documented deficits in categorical fluency, planning, monitoring and revising during problem solving, and response shifting using the flexibility task, the Go/No-go task, and the Tower of London task (e.g., Condor et al., 1995; Mati-Zissi and Zafiropoulou, 2001; Reiter et al., 2005; Swanson et al., 2006). Other authors have demonstrated that DD children were impaired in inhibition tasks such as the Stroop Test (Everatt et al., 1997; Brosnan et al., 2002; Reiter et al., 2005).

With few exceptions (Reiter et al., 2005; Willcutt et al., 2005; Swanson et al., 2006), the above-mentioned studies investigated each EF separately in DD.

However, in the last few years, a multifactorial deficit has been found, supporting the view that neurocognitive developmental dysfunctions in DD may not be limited to the linguistic brain areas, but may also involve a more multifocal cortical system (Pennington, 2006).

Recent functional neuroimaging findings provide evidence of a neurobiological signature for dyslexia, including two crucial posterior systems, one in the occipito-temporal regions and one in the parieto-temporal regions, as well as an anterior system, mainly located in the inferior frontal gyrus (Shaywitz et al., 2008).

The anterior system is implicated in the output of phonological and articulatory aspects, verbal working memory, and the semantic aspects of word reading (Price, 2000; Jobard et al., 2003; Gabrieli, 2009). It was recently suggested (Hoeft et al., 2007; Graves et al., 2010) that in both expert readers and dyslexics the contribution of this system to reading is primarily due to the attention, working memory and executive processes required by reading than to orthographical-phonological mapping per se.

The occipito-temporal system has a particularly important role in skilled, fluent reading (i.e., rapid and automatic identification of words) and encompasses the fusiform gyrus (Visual Word Form Area) and the middle and inferior temporal gyrus (Cohen et al., 2000; Vinckier et al., 2007). The parieto-temporal system includes the angular and the supramarginal gyri, and portions of the temporal lobe, such as the left superior temporal gyrus. This system is responsible for cross-modal relation of auditory and visual processes during reading and for the integration of letters and sounds.

To overcome the limitations of previous studies which evaluated each EF separately, the aim of the present study was to simultaneously test different EF domains in the same group of children with DD using numerous tasks.

Children with DD were then compared to children with typical reading (TR) abilities using a neuropsychological battery tapping several EF such as verbal phonological and categorical fluency, spoonerism abilities, visual-spatial and auditory attention, verbal, visual and spatial short-term memory, verbal WM, and visual shifting. To better understand the potential role of EF in reading, the relationships between EF measures and reading abilities were also explored.

\section{MATERIALS AND METHODS PARTICIPANTS}

The study included 60 children and adolescents with DD (27 females) and 65 children with TR abilities (28 females) matched for chronological and mental age.

The chronological age range was $8-17$ years for the DD group (mean $11.4 \pm 1.9 S D$ ) and 8 to 16 years for TR participants (mean $11.9 \pm 1.6 S D$ ). The diagnosis of DD was made when word or non-word reading speed and/or accuracy level was at least 2 standard deviations below the mean value for the scholar level. In a non-verbal intelligence test Colored Progressive Matrices (CPM; Raven, 1994) all DD participants had a performance level in the normal range (above 10th percentile; mean 29.28 $\pm 4 S D$ ).

The presence of Attention Deficit Hyperactivity Disorder was excluded by means of DSM-IV recommendations (American Psychiatric Association, 2000) and confirmed by behavioral rating scales filled out by parents (Cornoldi et al., 1996; Re and Cornoldi, 2009). Furthermore, none of the children with DD underwent any intensive or specific reading training.

Criteria for inclusion in the TR group were: (i) no reading delay in word and non-word reading tests; (ii) normal or corrected visual acuity; (iii) no Attention Deficit Hyperactivity Disorder diagnosis. In the above-mentioned non-verbal intelligence test (Raven, 1994), TR children had a performance level in the normal range (above 10th percentile; mean $29.83 \pm 3.53 S D$ ).

\section{DESIGN AND MATERIALS}

Children with DD were evaluated in three testing sessions carried out on three different days at the Department of Child and Adolescent Psychiatry of the Bambino Gesù Children's Hospital in Rome. TR children were assessed in three testing sessions in a local primary school. All tasks included a practice phase during which the experimenter explained the task instructions. Tasks were administered in a pseudorandom manner (IQ and reading abilities were always assessed before testing began). All the children's parents gave written informed consent after an extensive description of the research study. The neuropsychological battery involved IQ, reading abilities and EF tasks.

\section{GENERAL INTELLIGENCE}

Non-verbal intelligence was measured using the CPM (Raven, 1994), which evaluate the ability to form perceptual relations and to reason by analogy, irrespective of language and formal schooling.

\section{READING ABILITIES}

Reading abilities were assessed using two subtests of a battery for the diagnosis of DD (Sartori et al., 1995). Participants were asked to read aloud lists of words and non-words. Speed (in seconds) and errors (each incorrect word or non-word was calculated as one error) were computed for each task. Also, inefficiency reading indexes were considered, calculating the ratio between reading speed and accuracy rate (number of words/non-words correctly 
read over the total number of words/non-words) for both word and non-word reading tasks.

\section{EF TASKS}

\section{Verbal categorical fluency}

The Category fluency test (Vicari, 2007) was used to measure verbal fluency. Participants were asked to generate words in a particular category (e.g., animals, clothes, fruits, toys). Deviations from the test rules, including repetitions (perseveration errors) and words not identifiable as an example of the category, were considered errors. All words generated by the participants were recorded by the examiner, and the number of valid responses produced during the time limit $(60 \mathrm{~s})$ was calculated (excluding repetitions and errors). The score is calculated as the sum of the number of words generated for each category and the total number of responses.

\section{Verbal phonological fluency}

The Phonological Fluency Test (Marotta et al., 2008) was used to evaluate the ability to recall several items using a phonological input. In this task, the child was asked to verbalize as many words as possible beginning with a given phoneme (F, A, and S) within $60 \mathrm{~s}$ for each of the three trials. The global score is the sum of the correct responses for the three trials.

\section{Spoonerism}

The Spoonerism Task (Marotta et al., 2008) was used to evaluate phonological awareness. The examiner pronounced two words aloud and the participant had to swap the initial phonemes to form two new real words. The child was asked to transpose the beginning sounds of the two words as quickly as possible (time limit to complete a single trial: $60 \mathrm{~s}$; number of trials: 15). The score is the number of correct answers (maximum score: 30 ) and the time taken to complete the entire test (15 trials).

\section{Visual-spatial attention}

Selective visual-spatial attention was evaluated using the Map Mission. In this subtest of the Test of Everyday Attention for Children (Manly et al., 2001), a color-printed A3-laminated city map was presented. Eighty targets representing restaurants (i.e., small knife and fork symbols) were randomly distributed across the map. Distracting symbols of the same size were also present. Participants used a pen to circle as many targets as possible in $60 \mathrm{~s}$. The performance score is the number of target symbols correctly marked by the participants (maximum score: 80 ).

\section{Auditory attention}

Sustained auditory attention was investigated using the Code Transmission task. In this task, which was also a subtest of the Test of Everyday Attention for Children (Manly et al., 2001), participants were asked to monitor a stream of monotonous digits (presented at a rate of one every $2 \mathrm{~s}$ ) for the occurrence of a particular target sequence (e.g., 5, 5) and then to report the digit that occurred immediately before the target sequence. After a practice sequence to ensure comprehension, 40 targets were presented. The number of targets correctly detected is recorded as the measure of performance accuracy (maximum score: 40).

\section{Verbal short term and working memory}

To assess verbal short term memory and WM a verbal span task from an extensive memory battery was used (Vicari, 2007). The task consists of a list of eight, two-syllable low frequency words. In the first block, the examiner read aloud two words at a rate of one item per second. The participants were required to repeat the two words in the same order. Then, four additional strings of two words were presented. If the child was successful in at least three of the five sequences, a sequence one word longer was presented. If the child failed (less than three correct answers in a block), the task was discontinued. The same procedure was used for sequences of increasing length (up to a maximum of seven words). The score is computed by assigning 0.5 to each sequence of items correctly reproduced by the participant (maximum score: 17.5).

Moreover, a non-word repetition task (Vicari, 2007) was used to assess verbal WM. The number of non-words correctly repeated is recorded as a measure of performance accuracy (maximum score: 40 ).

\section{Spatial short term and working memory}

In the visual-spatial span task (Vicari, 2007), the material consisted of a non-verbalizable geometric shape that appears for $2 \mathrm{~s}$ in one of seven possible positions on the computer screen. Then, two empty cells were presented in the same spatial positions as before and the child had to indicate the order in which the stimuli appeared. If the child was successful in at least three of five two-position sequences, a sequence one block longer was presented. Also in this case, the same testing procedure was used for sequences of increasing length (up to a maximum of seven spatial positions). The score was computed by assigning 0.5 to each sequence of items correctly reproduced by the participant (maximum score: 17.5).

\section{Visual short term and working memory}

A similar procedure was used for the visual span task (Vicari, 2007). In this case, the experimental material consisted of seven complex geometric figures depicted in high contrast colors. Two figures were presented, one at time, for $2 \mathrm{~s}$ at the center of the computer screen. After the disappearance of the second figure, the two figures were presented aligned in the center of the screen in a random position and the participant was asked to indicate the order in which they appeared. Also in this case, if the child was successful in at least three of the five trials, a sequence one figure longer was presented and the task continued until a maximum of seven figures have been presented. The score is computed by assigning 0.5 to each sequence of items correctly reproduced by the participant (maximum score: 17.5 ).

\section{Visual shifting}

The Wisconsin Card Sorting Test (WCST; Heaton et al., 1993) is a neuropsychological test of set shifting and also involves cognitive flexibility function. The WCST consists of four stimulus cards and 128 response cards which differ in color (red, green, blue and yellow), shape (circle, star, cross, and star) and number (one, two, three, and four). The stimulus cards are one red triangle, two green stars, three yellow crosses, and four blue circles. 
The child was given the response cards and instructed to place each consecutive card under one of the stimulus cards, according to which he/she considered correct. After each sort, the child was informed whether he/she was correct. The first sorting category was color, and after 10 consecutive correct sorts, the category changed to form, without forewarning, and then accordingly to number. Errors in shifting from one category to another and perseveration errors are registered as scores.

\section{STATISTICAL ANALYSIS}

Data were analyzed using the Statistical Program for Windows, Version 8.0 (StatSoft, Inc., Tulsa, OK, USA). Participants' performances were transformed into $\mathrm{Z}$-scores. Since the assumptions of normality were not met, comparisons between DD and TR children on EF measures were carried out by means of the Kruskal-Wallis non parametric test with Group as independent between-subjects factor. To correct for multiple comparisons, the level of significance was set at $p=0.005$ using Bonferroni correction (10 comparisons).

Moreover, multiple regression analyses were computed to explore the linear relationship between EF measures (predictor variables) and reading abilities (criterion variable), using the stepwise method.

\section{RESULTS}

DD children obtained significantly lower scores ( $p$ always $\leq 0.005$ ) than TR children in phonological and categorical fluency, spoonerism abilities, visual-spatial and auditory attention, verbal and visual short-term memory, and verbal WM. For the level of significance adopted $(p=0.005)$, the comparisons of spatial short-term memory and shifting abilities showed no significant results (see Table $\mathbf{1}$ ).

To determine predictive relationships between EF measures (predictor variables) and inefficiency reading indexes (criterion variables), multiple regression analyses were computed using the stepwise method. Thus, each EF measure was entered in sequence as predictor variable and its value assessed to determine its contribution to the success of the model; variables that did not significantly contribute were automatically removed.

Overall, the first regression model, which included only spoonerism abilities (speed in seconds), accounted for $49.2 \%$ of the variance $\left(R^{2}\right.$ change $\left.=0.492\right)$ in words reading inefficiency index. The inclusion of auditory attention resulted in an additional $4.2 \%$ of the variance being explained $\left(R^{2}\right.$ change $\left.=0.042\right)$. The addition of visual-spatial attention explained a further $2.8 \%$ of the variance $\left(R^{2}\right.$ change $\left.=0.028\right)$.

Similarly to non-words reading inefficiency, the first regression model included only spoonerism abilities, accounting for $49.2 \%$ of the variance $\left(R^{2}\right.$ change $\left.=0.492\right)$. The inclusion of auditory attention explained an additional 3\% of the variance $\left(R^{2}\right.$ change $\left.=0.03\right)$, and the inclusion of visual-spatial attention accounted for a further $2 \%$ of the variance $\left(R^{2}\right.$ change $\left.=0.02\right)$. Table 2 summarizes multiple regression analyses for words and non-words reading inefficiency index.

\section{DISCUSSION}

This study was aimed at testing simultaneously different EF domains in a group of DD children. Deficits in several aspects of EF such as spoonerism, verbal categorical and phonological fluency, visual-spatial and auditory attention, verbal and visual short-term memory, and verbal WM have been found. However, spatial short-term memory and visual shifting abilities were preserved.

Consistent with previous studies, we observed a deficit in verbal phonological fluency (Goswami, 2000; Snowling, 2000; Ramus, 2003; Ramus et al., 2013) and in verbal categorical fluency (Snowling, 2000; Ramus et al., 2003; Reiter et al., 2005). These tasks engage complex cognitive mechanisms, such as WM, selfmonitoring, and flexible thinking (Troyer et al., 1998; Schwartz et al., 2003), and in addition require rapid access to words and strategic search through lexical/phonologic and conceptual/semantic memory (Baldo and Dronkers, 2006). Due to the several cognitive mechanisms involved, a large cortical network is required, including the dorsolateral prefrontal cortex and word associative fronto-temporal regions (Frith et al., 1991; Friston et al., 1991; Cilia et al., 2007; Kalbe et al., 2009).

We also found in children with DD a lower performance in the spoonerism task, which is generally used to assess phonological awareness. However, to interpret this result properly it is necessary to focus on the extra task demands and not only on phonological abilities (Wimmer et al., 2000). The child is first asked to segment the word into two parts, the first phoneme (onset) and

Table 1 | Performances of children with developmental dyslexia (DD) and with typical reading (TR) in executive functions tasks (after back-transformation to original measure units).

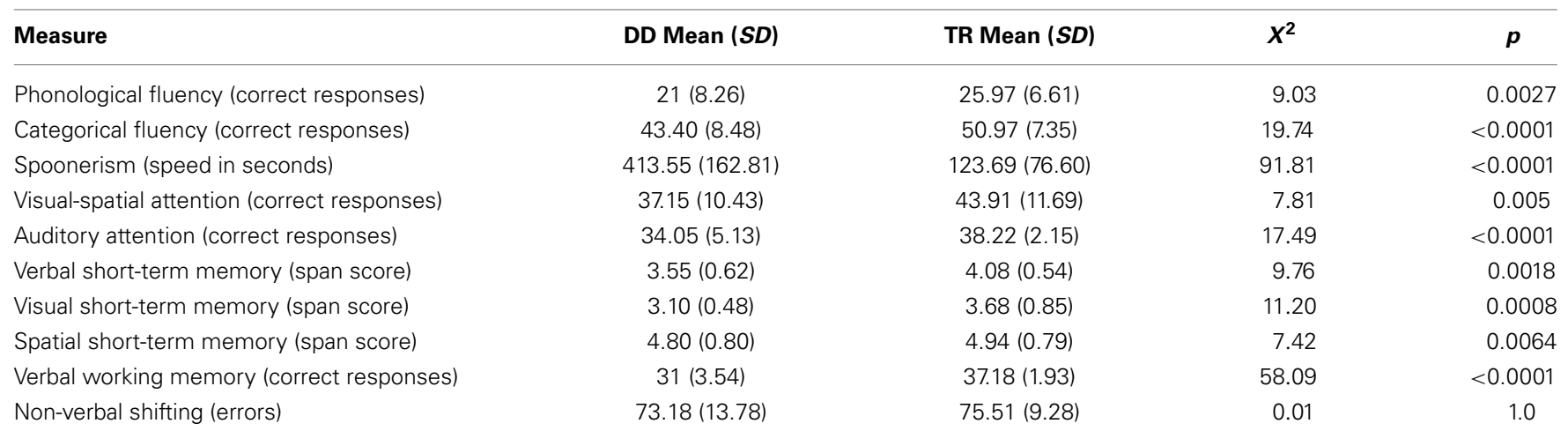


Table 2 | Multiple regression analysis predicting words and non-words reading inefficiency (only significant relationships are shown).

\begin{tabular}{|c|c|c|c|c|c|c|c|c|}
\hline \multirow[b]{2}{*}{ Predictor variable } & \multicolumn{4}{|c|}{ Words } & \multicolumn{4}{|c|}{ Non-words } \\
\hline & $\beta$ & $t$ for $\beta$ & $\boldsymbol{p}$ & Adjusted $R^{2}$ & $\beta$ & $t$ for $\beta$ & $\boldsymbol{p}$ & Adjusted $R^{2}$ \\
\hline Spoonerism (speed in seconds) & -0.55 & -7.956 & $<0.001$ & 0.488 & -0.575 & -8.122 & $<0.001$ & 0.488 \\
\hline Auditory attention (correct responses) & -0.204 & -3.052 & 0.003 & 0.527 & -0.171 & -2.493 & 0.014 & 0.514 \\
\hline Visual-spatial attention (speed in seconds) & -0.181 & -2.798 & 0.006 & 0.552 & -0.152 & -2.295 & 0.023 & 0.53 \\
\hline
\end{tabular}

the remainder of the word (rime), and temporally store the onset and rime of the first word; the child repeats this segmentation for a second word, and then blends the first onset with the second rime, and the second onset with the first rime. Therefore, the spoonerism task requires blending as well as segmentation skills, but also involves short-term and WM abilities, close monitoring of the phonological manipulation, and inhibitory processes. These complex demands could explain the deficits in tasks such as spoonerism usually found in dyslexic children (Jeffries and Everatt, 2004; Berninger et al., 2008; Kibby and Cohen, 2008; Menghini et al., 2011). It is worth noting that the spoonerism task, which involves all of these functions, has an important predictive role for both global and analytic reading skills.

Moreover, our results concerning attention support the hypothesis that both phonological processing and non-verbal processing are impaired in DD. Indeed, significant differences between DD and TR children were found in auditory and visualspatial attention domains. Although to a lesser extent, our results support the concept that auditory and visual-spatial attention explains an increased percentage of the variance related to reading disorders. A contribution of attention to reading, independent of the sensory modality considered, is then confirmed. Previous studies generally evaluated visual and auditory attention separately. Concerning visual attention, our results are consistent with reports of difficulties in rapidly focusing visual attention observed in individuals with DD (e.g., Brannan and Williams, 1987) as well as deficits in automatic control of visual attention (Facoetti et al., 2000, 2001, 2003; Hari and Renvall, 2001). Moreover, it was found that visual-spatial attention in preschoolers specifically predicts future reading acquisition (Franceschini et al., 2012), suggesting new approaches for early identification and efficient prevention of DD.

With respect to auditory attention, studies have clearly demonstrated auditory attentional deficits in DD (Asbjornsen and Bryden, 1998; Facoetti et al., 2000; Goswami, 2000; Ramus, 2003; Tallal, 2004; Ramus et al., 2013) which have been interpreted not only as a deficit in speech-sound perception (Cunningham et al., 2001) and in processing rapid sound sequences (Helenius et al., 1999), but also as a problem in shifting and focusing auditory attention (Renvall and Hari, 2002). The few studies assessing DD children on both modalities have documented multimodal (i.e., visual and auditory) attention deficits (Facoetti et al., 2000, 2003; Buchholz and McKone, 2004; Valdois et al., 2004; Dufor et al., 2007).

Furthermore, there is some evidence that in TR a visual dorsal pathway provides a mechanism for the early, preattentive visual analysis of words (Vidyasagar, 1999, 2001; Pammer et al., 2006;
Vidyasagar and Pammer, 2010). An adequate parsing of a stream of text into grapheme guides the grapheme-phoneme correspondence and the sensory integration of visual signals. For the proper identification of the graphemes and the subsequent matching of graphemes with phonemes, an attentional mechanism is required. The multimodal integration of visual and auditory inputs mediates the synthesis of orthographic and phonological information (Pammer et al., 2006).

In our group of dyslexic children a general multimodal (verbal and visual) deficit in short-term memory and WM has also been found. The results are at variance with the theory that dyslexic children have an isolated verbal short-term deficit, possibly secondary to a deficit of phonological processing or the expression of a dysfunctional articulatory loop (Poblano et al., 2000; Willcutt et al., 2001; Jeffries and Everatt, 2004; Kibby et al., 2004). By contrast, our results concord with data showing deficits in individuals with DD in the temporary storage of visual-spatial as well as verbal material (Poblano et al., 2000; Brosnan et al., 2002; Helland and Asbjørnsen, 2004; Martinussen and Tannock, 2006; SmithSpark and Fisk, 2007; Menghini et al., 2011). Our findings on WM can be interpreted as a deficient functioning of CES or SAS (Baddeley and Hitch, 1974; Norman and Shallice, 1986; Shallice and Burgess, 1993; Baddeley, 2000, 2001). Indeed, consistent with the model of WM, the failure of the CES to supervise the activity of both peripheral slave systems could fully account for poor performances in tasks involving different modalities as found in our dyslexic children.

Considering the several processes involved in the EF tasks adopted (e.g., attention, active-inhibition, temporary storage, maintenance, update and integration of information from several domain-specific codes) and their cross-modalities nature, deficits found in our dyslexic children could be the expression of a deficient functioning of CES/SAS. Therefore, we propose that a more global deficit in higher-order cognitive mechanisms might be a crucial feature of DD.

Additional support to this hypothesis is given by our findings which show that some EF tasks, primarily spoonerism but also auditory and visual-spatial attention, are strictly related to reading deficits in DD children. These data could confirm the contribution of the executive attention and domain-general attention control abilities (e.g., CES/SAS) to reading, irrespective of the sensory modality.

However, an additional hypothesis cannot be excluded. During recent years it has been proposed that DD arises from an abnormal auditory sampling (Goswami, 2011). Since cortical oscillations have been implicated in several aspects of human cognition, it has been assumed that the abnormal phonological processing 
observed in DD reflects a deficit in temporal sampling of speech by neuroelectric oscillation that encodes incoming information at different frequencies (Goswami, 2011). Indeed, temporal coding via the synchronous activity of oscillating networks of neurons at different frequency bands is crucial in the perceptual processing of speech (Luo and Poeppel, 2007). In dyslexics the auditory sampling might be altered, yielding phonemic representations of an unusual temporal format, with specific consequences for phonological processing and phoneme/grapheme associations (Lehongre et al., 2011).

Similarly, studying high-frequency auditory oscillations associated with verbal WM, Lehongre et al. (2011) found that dyslexics exhibited a supranormal entrainment of bilateral planum temporal to fast temporal modulations in the $50-70 \mathrm{~Hz}$ range. It has been hypothesized (Lehongre et al., 2011) that in dyslexics too fast low-gamma oscillations might flood the auditory system with overdetailed spectrotemporal information, thereby saturating theta-based auditory buffer capacity and verbal WM. However, the relationship between neuronal oscillations and nonverbal WM correlates is still an open issue in DD.

Finally, the cellular synchronization of oscillatory responses might be responsible for the above mentioned multimodal integration of visual and auditory inputs which mediates the synthesis of orthographic and phonological information (Gray et al., 1989). Indeed, changes in gamma-band signals have been implicated in cognitive integration of stimuli (Pulvermüller et al., 1997; Ward, 2003; Hermann et al., 2004) and alpha-band activity contributes to specific attentional processes such as attentional selection and filter. Moreover, alpha power is larger over visual cortices when attention is focused on the auditory part of a multimodal auditory-visual stimulus (Klimesch, 2012). So, different frequency domains might interact in terms of cross-frequency coupling of oscillations, with cross-modal knock-on effects. One possibility is that atypical cross-frequency coupling in DD might interfere with the attentional mechanism for the multimodal integration of visual and auditory inputs.

In conclusion, our findings support the hypothesis that DD is a multiple neurocognitive deficit and not solely related to a phonological system dysfunction. The relation of brain oscillation to EF networks remains to be explored and could be useful for the further development of current neurophysiological models of DD.

\section{REFERENCES}

Abad-Mas, L., Ruiz-Andrés, R., Moreno-Madrid, F., Sirera-Conca, M. A., Cornesse, M., Delgado-Mejía, I. D., et al. (2011). Executive function training in attention deficit hyperactivity disorder. Rev. Neurol. 52, 77-83.

Alloway, T. P., and Alloway, R. G. (2013). Working memory in the lifespan: a crosssectional approach. J. Cogn. Psychol. 25, 84-93. doi: 10.1080/20445911.2012. 748027

Altemeier, L. E., Abbott, R. D., and Berninger, V. W. (2008). Executive functions for reading and writing in typical literacy development and dyslexia. J. Clin. Exp. Neuropsychol. 30, 588-606. doi: 10.1080/13803390701562818

American Psychiatric Association (APA). (2000). Diagnostic and Statistical Manual of Mental Disorders: Text Revision (DSM-IV-TR). Washington, DC: American Psychological Association.

Asbjornsen, A. E., and Bryden, M. P. (1998). Auditory attentional shifts in readingdisabled students: quantification of attentional effectiveness by the attentional shift index. Neuropsychologia 36, 143-148. doi: 10.1016/S0028-3932(97) 00090-0
Bacon, A. M., Parmentier, F. B., and Barr, P. (2013). Visuospatial memory in dyslexia: evidence for strategic deficits. Memory 21, 189-209. doi: 10.1080/09658211.2012.718789

Baddeley, A. D. (2000). The episodic buffer: a new component of WM? Trends Cogn. Sci. 4, 417-423. doi: 10.1016/S1364-6613(00)01538-2

Baddeley, A. D. (2001). Is working memory still working? Am. Psychol. 56, 851-864. doi: 10.1037/0003-066X.56.11.851

Baddeley, A. D., and Hitch, G. (1974). "Working memory," in The Psychology of Learning and Motivation: Advances in Research and Theory, ed G. H. Bower (New York, NY: Academic Press), 47-89.

Baddeley, A. D., and Logie, R. H. (1999). "Working memory: the multiple component model," in Models of Working Memory: Mechanisms of Active Maintenance and Executive Control, eds A. Miyake and P. Shah (New York, NY: Cambridge University Press), 28-61. doi: 10.1017/CBO9781139174909.005

Baldo, J. V., and Dronkers, N. F. (2006). The role of inferior parietal and inferior frontal cortex in working memory. Neuropsychology 20, 529-538. doi: 10.1037/0894-4105.20.5.529

Berninger, V. W., Raskind, W., Richards, T., Abbott, R., and Stock, P. (2008). A multidisciplinary approach to understanding developmental dyslexia within working-memory architecture: genotypes, phenotypes, brain, and instruction. Dev. Neuropsychol. 33, 707-744. doi: 10.1080/87565640802418662

Booth, J. N., Boyle, J. M., and Kelly, S. W. (2010). Do tasks make a difference? Accounting for heterogeneity of performance of children with reading difficulties on tasks of executive function: findings from a meta-analysis. Br. J. Dev. Psychol. 28, 133-176. doi: 10.1348/026151009X485432

Brannan, J. R., and Williams, M. C. (1987). Allocation of visual attention in good and poor readers. Percept. Psychophys. 41, 23-28. doi: 10.3758/BF03208209

Brosnan, M., Demetre, J., Hamill, S., Robson, K., Shepherd, H., and Cody, G. (2002). Executive functioning in adults and children with developmental dyslexia. Neuropsychologia 40, 2144-2155. doi: 10.1016/S0028-3932(02)00046-5

Buchholz, J., and McKone, E. (2004). Adults with dyslexia show deficits on spatial frequency doubling and visual attention tasks. Dyslexia 10, 24-43. doi: 10.1002/dys.263

Casco, C., and Prunetti, E. (1996). Visual search of good and poor readers: effects with targets having single and combined features. Percept. Mot. Skills 82, 1155-1167. doi: 10.2466/pms.1996.82.3c.1155

Cilia, R., Siri, C., Marotta, G., De Gaspari, D., Landi, A., Mariani, C. B., et al. (2007). Brain networks underlining verbal fluency decline during STN-DBS in Parkinson's disease: an ECD-SPECT study. Parkinsonism Relat. Disord. 13, 290-294. doi: 10.1016/j.parkreldis.2006.11.011

Cohen, L., Dehaene, S., Naccache, L., Lehericy, S., Dehaene-Lambertz, G., and Henaff, M. A. (2000). The visual word form area: spatial and temporal characterization of an initial stage of reading in normal subjects and posterior split-brain patients. Brain 123, 291-307. doi: 10.1093/brain/123.2.291

Condor, A., Anderson, V., and Saling, M. (1995). Do reading disabled children have planning problem? Dev. Neuropsychol. 11, 485-502. doi: 10.1080/87565649509540633

Corbett, B. A., Constantine, L. J., Hendren, R., Rocke, D., and Ozonoff, S. (2009). Examining executive functioning in children with autism spectrum disorder, attention deficit hyperactivity disorder and typical development. Psychiatry Res. 166, 210-222. doi: 10.1016/j.psychres.2008.02.005

Cornoldi, C., Gardinale, M., Masi, A., and Pettenò, L. (1996), Impulsività e autocontrollo. Trento: Erickson.

Costanzo, F., Varuzza, C., Menghini, D., Addona, A., Gianesini, T., and Vicari, S. (2013). Executive functions in intellectual disabilities: a comparison between Williams syndrome and Down syndrome. Res. Dev. Disabil. 34, 1770-1780. doi: 10.1016/j.ridd.2013.01.024

Cunningham, J., Nicol, T., Zecker, S. G., Bradlow, A., and Kraus, N. (2001). Neurobiologic responses to speech in noise in children with learning problems: deficits and strategies for improvement. Clin. Neurophysiol. 112, 758-767. doi: 10.1016/S1388-2457(01)00465-5

Dufor, O., Serniclaes, W., Sprenger-Charolles, L., and Démonet, J. F. (2007). Topdown processes during auditory phoneme categorization in dyslexia: a PET study. Neuroimage 15, 1692-1707. doi: 10.1016/j.neuroimage.2006.10.034

Everatt, J., Warner, J., and Miles, T. R. (1997). The incidence of stroop interference in dyslexia. Dyslexia 3, 222-228.

Facoetti, A., Lorusso, M. L., Paganoni, P., Cattaneo, C., Galli, R., and Mascetti, G. G. (2003). The time course of attentional focusing in dyslexic and normally reading children. Brain Cogn. 53, 181-184. doi: 10.1016/S0278-2626(03)00105-2 
Facoetti, A., Paganoni, P., Turatto, M., Marzola, V., and Mascetti, G. G. (2000). Visual-spatial attention in developmental dyslexia. Cortex 36, 109-123. doi: 10.1016/S0010-9452(08)70840-2

Facoetti, A., Turatto, M., Lorusso, M. L., and Mascetti, G. G. (2001). Orienting of visual attention in dyslexia: evidence for asymmetric hemispheric control of attention. Exp. Brain Res. 138, 46-53. doi: 10.1007/s002210100700

Franceschini, S., Gori, S., Ruffino, M., Pedrolli, K., and Facoetti, A. (2012). A causal link between visual spatial attention and reading acquisition. Curr. Biol. 22, 814-819. doi: 10.1016/j.cub.2012.03.013

Friedman, N. P., Miyake, A., Corley, R. P., Young, S. E., De Fries, J. D., and Hewitt, J. K. (2006). Not all executive functions are related to intelligence. Psychol. Sci. 17, 172-179. doi: 10.1111/j.1467-9280.2006.01681.x

Friston, K. J., Frith, C. D., Liddle, P. F., and Frackowiak, R. S. (1991). Investigating a network model of word generation with positron emission tomography. Proc. Biol. Sci. 244, 101-106. doi: 10.1098/rspb.1991.0057

Frith, C. D., Friston, K. J., Liddle, P. F., and Frackowiak, R. S. (1991). A PET study of word finding. Neuropsychologia 29, 1137-1148. doi: 10.1016/00283932(91)90029-8

Gabrieli, J. D. (2009). Dyslexia: a new synergy between education and cognitive neuroscience. Science 17, 280-283. doi: 10.1126/science.1171999

Goswami, U. (2000). Phonological representations, reading development and dyslexia: towards a cross-linguistic theoretical framework. Dyslexia 6, 133-151. doi: 10.1002/(SICI) 1099-0909(200004/06)6:2<133::AID-DYS160>3.0.CO;2-A

Goswami, U. (2011). A temporal sampling framework for developmental dyslexia. Trends Cogn. Sci. 15, 3-10. doi: 10.1016/j.tics.2010.10.001

Graves, L. E., Ridgers, N. D., Williams, K., Stratton, G., Atkinson, G., and Cable, N. T. (2010). The physiological cost and enjoyment of Wii Fit in adolescents, young adults, and older adults. J. Phys. Act. Health 7, 393-401.

Gray, C. M., König, P., Engel, A. K., and Singer, W. (1989). Oscillatory responses in cat visual cortex exhibit inter-columnar synchronization which reflects global stimulus properties. Nature 338, 334-337. doi: 10.1038/338334a0

Green, C. R., Mihic, A. M., Nikkel, S. M., Stade, B. C., Rasmussen, C., Munoz, D. P., et al. (2009). Executive function deficits in children with fetal alcohol spectrum disorders (FASD) measured using the Cambridge Neuropsychological Tests Automated Battery (CANTAB). J. Child Psychol. Psychiatry 50, 688-697. doi: 10.1111/j.1469-7610.2008.01990.x

Hari, R., and Renvall, H. (2001). Impaired processing of rapid stimulus sequences in dyslexia. Trends Cogn. Sci. 5, 525-532. doi: 10.1016/S1364-6613(00)01801-5

Heaton, R. K., Chelune, G. J., Talley, J. L., Kay, G. G., and Curtis, G. (1993). Wisconsin Card Sorting Test (WCST) Manual, Revised and Expanded. Odessa, FL: Psychological Assessment Resources.

Helenius, P., Uutela, K., and Hari, R. (1999). Auditory stream segregation in dyslexic adults. Brain 122, 907-913. doi: 10.1093/brain/122.5.907

Helland, T., and Asbjørnsen, A. (2000). Executive functions in dyslexia. Child Neuropsychol. 6, 37-48. doi: 10.1076/0929-7049(200003)6:1;1-B;FT037

Helland, T., and Asbjørnsen, A. (2004). Digit span in dyslexia: variations according to language comprehension and mathematics skills. J. Clin. Exp. Neuropsychol. 26, 31-42. doi: 10.1076/jcen.26.1.31.23935

Hermann, C., Munk, M., and Engel, A. (2004). Cognitive functions of gammaband activity: memory match and utilization. Trends Cogn. Sci. 8, 347-533. doi: 10.1016/j.tics.2004.06.006

Hill, E. L. (2004). Executive dysfunction in autism. Trends Cogn. Sci. 8, 26-32. doi: 10.1016/j.tics.2003.11.003

Hoeft, F., Ueno, T., Reiss, A. L., Meyler, A., Whitfield-Gabrieli, S., Glover, G. H., et al. (2007). Prediction of children's reading skills using behavioral, functional and structural neuroimaging measures. Neuroscience 121, 602-613. doi: 10.1037/0735-7044.121.3.602

Jeffries, S., and Everatt, J. (2004).Working memory: its role in dyslexia and other specific learning difficulties. Dyslexia 10, 196-214. doi: 10.1002/dys.278

Jobard, G., Crivello, F., and Tzourio-Mazoyer, N. (2003). Evaluation of the dual route theory of reading: a metanalysis of 35 neuroimaging studies. Neuroimage 20, 693-712. doi: 10.1016/S1053-8119(03)00343-4

Kalbe, E., Voges, J., Weber, T., Haarer, M., Baudrexel, S., Klein, J. C., et al. (2009). Frontal FDG-PET activity correlates with cognitive outcome after STN-DBS in Parkinson disease. Neurology 72, 42-49. doi: 10.1212/01.wnl.0000338536.31388.f0

Kane, M. J., Bleckley, M. K., Conway, A. R., and Engle, R. W. (2001). A controlledattention view of working-memory capacity. J. Exp. Psychol. Gen. 130, 169-183. doi: 10.1037/0096-3445.130.2.169
Kane, M. J., and Engle, R. W. (2002). The role of prefrontal cortex in working-memory capacity, executive attention, and general fluid intelligence: an individual-differences perspective. Psychon. Bull. Rev. 9, 637-671. doi: 10.3758/BF03196323

Kenworthy, L. E., Black, D. O., Wallace, G. L., Ahluvalia, T., Wagner, A. E., and Sirian, L. M. (2005). Disorganization: the forgotten executive dysfunction in high-functioning autism (HFA) spectrum disorders. Dev. Neuropsychol. 28, 809-827. doi: 10.1207/s15326942dn2803_4

Kibby, M. Y., and Cohen, M. J. (2008). Memory functioning in children with reading disabilities and/or attention deficit/hyperactivity disorder: a clinical investigation of their working memory and long-term memory functioning. Child Neuropsychol. 31, 1-22. doi: 10.1080/09297040701821752

Kibby, M. Y., Marks, W., Morgan, S., and Long, C. J. (2004). Specific impairment in developmental reading disabilities: a working memory approach. J. Learn. Disabil. 37, 349-363. doi: 10.1177/00222194040370040601

Klimesch, W. (2012). Alpha-band oscillations, attention, and controlled access to stored information. Trends Cogn. Sci. 16, 606-617. doi: 10.1016/j.tics.2012.10.007

Laasonen, M., Salomaa, J., Cousineau, D., Leppämäki, S., Tani, P., Hokkanen, L., et al. (2012). Project DyAdd: visual attention in adult dyslexia and ADHD. Brain Cogn. 80, 311-327. doi: 10.1016/j.bandc.2012.08.002

Lehongre, K., Ramus, F., Villiermet, N., Schwartz, D., Pressnitzer, D., and Giraud, A. L. (2011). Altered cortical entrainment to fast acoustic modulations reflect phonological and working memory deficit in dyslexia. Neuron 72, 1080-1090. doi: 10.1016/j.neuron.2011.11.002

Luo, H., and Poeppel, D. (2007). Phase patterns of neuronal responses reliably discriminate speech in human auditory cortex. Neuron 54, 1001-1010. doi: 10.1016/j.neuron.2007.06.004

Manly, T., Anderson, V., Nimmo-Smith, I., Turner, A., Watson, P., and Robertson, I. H. (2001). The differential assessment of Children's attention: the Test of Everyday Attention for Children (TEA-Ch), normal sample and ADHD performance. J. Child Psychol. Psychiatry 42, 1065-1081. doi: 10.1111/14697610.00806

Marotta, L., Trasciani, M., and Vicari, S. (2008). Test CMF. Valutazione Delle Competenze Metafonologiche. Trento: Erickson.

Martinussen, R., and Tannock, R. (2006). Working memory impairments in children with attention-deficit hyperactivity disorder with and without comorbid language learning disorders. J. Clin. Exp. Neuropsychol. 28, 1073-1094. doi: $10.1080 / 13803390500205700$

Mati-Zissi, H., and Zafiropoulou, M. (2001). Drawing performance in prediction of special learning difficulties of kindergarten children. Percept. Mot. Skills 92, 1154-1166. doi: 10.2466/pms.2001.92.3c.1154

Menghini, D., Finzi, A., Benassi, M., Bolzani, R., Facoetti, A., Giovagnoli, S., et al. (2010). Different underlying neurocognitive deficits in developmental dyslexia: a comparative study. Neuropsychologia 48, 863-872. doi: 10.1016/j.neuropsychologia.2009.11.003

Menghini, D., Finzi, A., Carlesimo, G. A., and Vicari S. (2011). Working memory impairment in children with developmental dyslexia: is it just a phonological deficit? Dev. Neuropsychol. 36, 199-213. doi: 10.1080/87565641.2010.549868

Norman, W., and Shallice, T. (1986). "Attention to action," in Consciousness and Self Regulation: Advances in Research and Theory, eds R. J. Davidson, G. E. Schwartz, and D. Shapiro (New York, NY: Plenum), 1-18. doi: 10.1007/978-1-47570629-1_1

Pammer, K., Hansenc, P., Hollidayd, I., and Cornelissenb, P. (2006). Attentional shifting and the role of the dorsal pathway in visual word recognition. Neuropsychologia 44, 2926-2936. doi: 10.1016/j.neuropsychologia.2006.06.028

Pani, P., Menghini, D., Napolitano, C., Calcagni, M., Armando, M., Sergeant, J. A., et al. (2013). Proactive and reactive control of movement are differently affected in attention deficit hyperactivity disorder children. Res. Dev. Disabil. 34, 3104-3111 doi: 10.1016/j.ridd.2013.06.032

Pei, J., Job, J., Kully-Martens, K., and Rasmussen, C. (2011). Executive function and memory in children with fetal alcohol spectrum disorder. Child Neuropsychol. 17, 290-309. doi: 10.1080/09297049.2010.544650

Pennington, B. F. (2006). From single to multiple deficit models of developmental disorders. Cognition 101, 385-413. doi: 10.1016/j.cognition.2006. 04.008

Pennington, B. F., and Ozonoff, S. (1996). Executive functions and developmental psychopathology. J. Child Psychol. Psychiatry 37, 51-87. doi: 10.1111/j.14697610.1996.tb01380.x 
Poblano, A., Valadéz-Tepec, T., de Lourdes Arias, M., and García-Pedroza, F. (2000). Phonological and visuo-spatial working memory alterations in dyslexic children. Arch. Med. Res. 31, 493-496. doi: 10.1016/S0188-4409(00) 00096-5

Price, C. J. (2000). The anatomy of language: contributions from functional neuroimaging. J. Anat. 197, 335-359. doi: 10.1046/j.1469-7580.2000.19730335.x

Pulvermüller, F., Birbaumer, N., Lutzenberger, W., and Mohr, B. (1997). Highfrequency brain activity: its possible role in attention, perception and language processing. Prog. Neurobiol. 52, 427-445. doi: 10.1016/S0301-0082(97) 00023-3

Ramus, F. (2003). Developmental dyslexia: specific phonological deficit or general sensorimotor dysfunction? Curr. Opin. Neurobiol. 13, 212-218. doi: 10.1016/S0959-4388(03)00035-7

Ramus, F., Marshall, C. R., Rosen, S., and van der Lely, H. K. (2013). Phonological deficits in specific language impairment and developmental dyslexia: towards a multidimensional model. Brain 136, 630-645. doi: 10.1093/brain/aws356

Ramus, F., Rosen, S., Dakin, S. C., Day, B. L., Castellone, J. M., White, S., et al. (2003). Theories of developmental dyslexia: insights from a multiple case study of dyslexic adults. Brain 126, 841-865. doi: 10.1093/brain/awg076

Rasmussen, C. (2005). Executive functioning and working memory in fetal alcohol spectrum disorder. Alcohol Clin. Exp. Res. 29, 1359-1367. doi: 10.1097/01.alc.0000175040.91007.d0

Raven, J. C. (1994). CPM, Coloured Progressive Matrices, Series A, AB, B. Firenze: Giunti Organizzazioni Speciali. (Italian Adaptation).

Re, A. M., and Cornoldi, C. (2009). Two new rating scales for assessment of ADHD symptoms in Italian preschool children. J. Atten. Disord. 12, 532-539. doi: 10.1177/1087054708323001

Reiter, A., Tucha, O., and Lange, K. W. (2005). Executive functions in children with dyslexia. Dyslexia 10, 1-16. doi: 10.1002/dys.289

Renvall, H., and Hari, R. (2002). Auditory cortical responses to speechlike stimuli in dyslexic adults. J. Cogn. Neurosci. 14, 757-768. doi: 10.1162/08989290260138654

Rinehart, N. J., Bradshaw, J. L., Moss, S. A., Brereton, A. V., and Tonge, B. J. (2001). A deficit in shifting attention present in high-functioning autism but not Asperger's disorder. Autism 5, 67-80. doi: 10.1177/1362361301005001007

Robinson, S., Goddard, L., Dritschel, B., Wisley, M., and Howlin, P. (2009). Executive functions in children with autism spectrum disorders. Brain Cogn. 71, 362-368. doi: 10.1016/j.bandc.2009.06.007

Sartori, G., Job, R., and Tressoldi, P. E. (1995). Batteria per la Valutazione Della Dislessia e Della Disortografia Evolutiva. Firenze: Giunti Organizzazioni Speciali.

Schwartz, S., Baldo, J., Graves, R. E., and Brugger, P. (2003). Pervasive influence of semantics in letter and category fluency: a multidimensional approach. Brain Lang. 87, 400-411. doi: 10.1016/S0093-934X(03)00141-X

Sergeant, J. A., Geurts, H., and Oosterlaan, J. (2002). How specific is a deficit of executive functioning for attention-deficit/hyperactivity disorder? Behav. Brain Res. 130, 3-28. doi: 10.1016/S0166-4328(01)00430-2

Shallice, T., and Burgess, P. W. (1993). "Supervisory control of action and thought selection," in Attention: Selection, Awareness and Control, eds A. D. Baddeley and L. Weiskrantz (Oxford: Clarendon Press), 171-187.

Shaywitz, S. E., Morris, R., and Shaywitz, B. A. (2008). The education of dyslexic children from childhood to young adulthood. Annu. Rev. Psychol. 59, 451-475. doi: 10.1146/annurev.psych.59.103006.093633

Smith-Spark, J. H., and Fisk, J. E. (2007). Working memory functioning in developmental dyslexia. Memory 15, 34-56. doi: 10.1080/09658210601043384

Smith-Spark, J., H., Fisk, J., Fawcett, A. J., and Nicolson, R. I. (2003). Investigating the central executive in adult dyslexics: evidence from phonological and visuospatial working memory performance. Eur. J. Cogn. Psychol. 15, 567-587. doi: 10.1080/09541440340000024

Snowling, M. J. (2000). Dyslexia: a Cognitive-Developmental Perspective. Oxford: Blackwell.

Swanson, H. L., Howard, C. B., and Sáez, L. (2006). Do different components of working memory underlie different subgroups of reading disabilities? J. Learn. Disabil. 39, 252-269. doi: 10.1177/00222194060390030501
Swanson, H. L., Kehler, P., and Jerman, O. (2010). Working memory, strategy knowledge, and strategy instruction in children with reading disabilities. J. Learn. Disabil. 43, 24-47. doi: 10.1177/0022219409338743

Swanson, H. L., Zheng, X., and Jerman, O. (2009). Working memory, short-term memory, and reading disabilities: a selective meta-analysis of the literature. J. Learn. Disabil. 42, 260-287. doi: 10.1177/0022219409331958

Tallal, P. (2004). Improving language and literacy is a matter of time. Nat. Rev. Neurosci. 5, 721-728. doi: 10.1038/nrn1499

Troyer, A. K., Moscovitch, M., Winocur, G., Alexander, M. P., and Stuss, D. (1998). Clustering and switching on verbal fluency: the effects of focal frontaland temporal-lobe lesions. Neuropsychologia 36, 499-504. doi: 10.1016/S00283932(97)00152-8

Valdois, S., Bosse, M. L., and Tainturier, M. J. (2004). The cognitive deficits responsible for developmental dyslexia: review of evidence for a selective visual attentional disorder. Dyslexia 10, 339-363. doi: 10.1002/dys.284

Vicari, S. (2007). PROMEA. Prove di Memoria e Apprendimento per l'Eta Evolutiva. Una Batteria Globale di Valutazione Della Memoria per Bambini dai 5 agli 11 anni. Firenze: Giunti Organizzazioni Speciali.

Vidyasagar, T. R. (1999). A neuronal model of attentional spotlight: parietal guiding the temporal. Brain Res. Rev. 30, 66-76. doi: 10.1016/S0165-0173(99)00005-3

Vidyasagar, T. R. (2001). From attentional gating in macaque primary visual cortex to dyslexia in humans. Progr. Brain Res. 134, 297-312. doi: 10.1016/S00796123(01)34020-7

Vidyasagar, T. R., and Pammer, K. (2010) Dyslexia: a deficit in visuospatial attention, not in phonological processing. Trends Cogn. Sci. 14, 57-63. doi: 10.1016/j.tics.2009.12.003

Vinckier, F., Dehaene, S., Jobert, A., Dubus, J. P., Sigman, M., and Cohen, L. (2007). Hierarchical coding of letter strings in the ventral stream: dissecting the inner organization of the visual word-form system. Neuron 55, 143-156. doi: 10.1016/j.neuron.2007.05.031

Ward, L. (2003). Synchronous neural oscillations and cognitive processes. Trends Cogn. Sci. 7, 553-559. doi: 10.1016/j.tics.2003.10.012

Welsh, M. C., Pennington, B. F., and Groisserc, D. B. (1991). A normativedevelopmental study of executive function: a window on prefrontal function in children. Dev. Neuropsychol. 7, 131-149. doi: 10.1080/87565649109540483

Willcutt, E. G., Pennington, B. F., Boada, R., Ogline, J. S., Tunick, R. A., Chhabildas, N. A., et al. (2001). A comparison of the cognitive deficits in reading disability and attention-deficit/hyperactivity disorder. J. Abnorm. Psychol. 110, 157-172. doi: 10.1037/0021-843X.110.1.157

Willcutt, E. G., Pennington, B. F., Olson, R. K., Chhabildas, N., and Hulslander, J. (2005). Neuropsychological analyses of comorbidity between reading disability and attention deficit hyperactivity disorder: in search of the common deficit. Dev. Neuropsychol. 27, 35-78. doi: 10.1207/s15326942dn2701_3

Wimmer, H., Mayringer, H., and Landerl, K. (2000). The double-deficit hypothesis and difficulties in learning to read a regular orthography. J. Educ. Psychol. 92, 668-680. doi: 10.1037/0022-0663.92.4.668

Conflict of Interest Statement: The authors declare that the research was conducted in the absence of any commercial or financial relationships that could be construed as a potential conflict of interest.

Received: 05 September 2013; accepted: 18 February 2014; published online: 07 March 2014.

Citation: Varvara P, Varuzza C, Sorrentino ACP, Vicari S and Menghini D (2014) Executive functions in developmental dyslexia. Front. Hum. Neurosci. 8:120. doi: 10.3389/fnhum.2014.00120

This article was submitted to the journal Frontiers in Human Neuroscience. Copyright (c) 2014 Varvara, Varuzza, Sorrentino, Vicari and Menghini. This is an open-access article distributed under the terms of the Creative Commons Attribution License (CC BY). The use, distribution or reproduction in other forums is permitted, provided the original author(s) or licensor are credited and that the original publication in this journal is cited, in accordance with accepted academic practice. No use, distribution or reproduction is permitted which does not comply with these terms. 